\title{
Hemangiopericytoma in the Small Intestine: A Case Report
}

\author{
B. Coha D. Krizanovic Z. Perusinovic S. Marinic \\ K. Jakovina \\ Dr. J. Bencevic General Hospital, Slavonski Brod, Croatia
}

\section{Key Words}

Hemangiopericytoma. Small intestine

\begin{abstract}
Hemangiopericytoma is a rare tumor, mostly composed of pericytes of ramified appearance that are normally found all along the venules and capillaries. An 18-year-old female was admitted on March 17, 1997 to the Department of Infectious Diseases for fever, chills and failure to thrive. Physical examination revealed a palpable tumorous mass in the iliac region on the right. The patient was transferred to the Department of Surgery. Vaginal examination and echotomography of the abdomen and pelvis minor were performed and revealed the presence of an irregular, inhomogeneous tumorous formation of $8 \mathrm{~cm}$ in diameter in the pelvis minor, differentially diagnostic right ovary, i.e. acute adnexitis or perityphlitic tumor. After that, small intestine resection, tumor excision in toto, and appendectomy were performed on April 16, 1997. Pathohistological diagnosis was hemangiopericytoma and chronic appendicitis. The biological behavior of this tumor is difficult to predict on the basis of clinical and morphological parameters. In our patient, local tumor excision was not followed by adjuvant therapy. After ten years, the patient is well, healthy and a mother of two healthy children.
\end{abstract}

\section{Introduction}

Hemangiopericytoma is a rare tumor, first described in 1942, mostly composed of pericytes of ramified appearance that are normally found all along the venules and capillaries [1]. Hemangiopericytoma may arise anywhere. It is usually seen in adults, although infantile hemangiopericytoma is also recognized. The adult form is most common in the lower extremities, but also occurs in the pelvis or retroperitoneum or other sites [2]. Males and females show equal frequencies of occurrence. The development of hemangiopericytoma in the small bowel (ileum) is rare, with only few cases reported in the literature until the end of 2007. The clinical diagnosis and prognosis of the clinical and biological behavior of the tumor based on its morphological features still pose a considerable challenge [3-5]. Many hemangiopericytomas have an indolent behavior, 
although some behave like other high-grade sarcomas. Immunohistochemically tumor cells stain with vimentin, but not with cytokeratin or epithelial membrane antigen. Vimentin is the main intermediate filament protein in mesenchymal cells, and therefore is of value in the differential diagnosis of undifferentiated neoplasms, including melanoma and sarcoma. Cytokeratin and epithelial membrane antigen are useful for marking tumors for squamous carcinoma and adenocarcinoma. Hemangiopericytoma is generally treated by extensive tumor excision with adjuvant radiotherapy and chemotherapy.

\section{Case Report}

An 18-year-old female was admitted on March 17, 1997 to the Department of Infectious Diseases of our hospital for fever, chills and failure to thrive. Physical examination revealed a palpable tumorous mass in the iliac region on the right. Laboratory findings are shown in table 1. Other laboratory findings were unremarkable.

Suspicion of acute adnexitis was confirmed after gynecological examination. Vaginal and abdominal ultrasound were done as well. Abdomen and pelvis minor echotomographic examination (ig. 1 ) revealed an oval mass about $8 \mathrm{~cm}$ in diameter, isoechoic to the surrounding tissue, with sharp margins, a central hypoechoic zone (possible necrosis) and a thin hypoechoic halo. Echotomographically it was unclear whether the described mass originated from the ovary or the small bowel.

After transfer to the Department of Surgery, laparotomy was performed which revealed a great vascular tumor of the ileum without infiltration to any adjacent organs or structure. The tumor did not break small bowel serosa. Small intestine resection, tumor excision in toto, and appendectomy were performed on April 16, 1997. There were no evident peritoneal or liver metastases. Also the right ovary and uterus were normal. Chronic appendicitis was an incidental finding. Macroscopically, a large $(10 \mathrm{~cm})$ shallow growth containing blood, surrounded by grayish to whitish tumor with visible nodules of cerebral consistency showing areas of hemorrhage, was found.

Histological examination revealed a tumor composed of dense, round-oval and spindle cells focally palisading without forming fascicular architecture. The tumor cells bordering vascular and sinusoid areas varied in size. Tumor cells were separated from the lumina by Gomori and PAS positive zone (fig. 2). The number of mitosis was $4 / 10$ high power fields. Immunohistochemically the tumor cells were positive for vimentin and negative for both types of actin, S-100, epithelial membrane antigen and antichimotrypsin. These findings confirmed a diagnosis of hemangiopericytoma, and the resection margin was clear. The resected appendix demonstrated chronic appendicitis.

The patient made a satisfactory recovery and was discharged on postoperative day 8 with a recommendation to visit the oncologist. Adjuvant chemotherapy was not indicated, but considering the possibility of recurrences after long periods, patient monitoring was established: trimestrial controls during the first postoperative year (physical examination, routine laboratory tests and abdominal echotomography), semiannual controls during the next two years and after that annual controls. Computed tomography of the abdomen and chest roentgenogram, performed three years after the operation, were both normal. Physical examination, abdominal echotomography, abdominal computed tomography and barium enema made five and ten years after the operation were normal. Signs of recurrence and/or metastases were not determined either. During the period of monitoring, the patient gave birth to two healthy children.

\section{Discussion}

The biological behavior of hemangiopericytoma is difficult to predict on the basis of clinical and morphological parameters. Obviously there are low malignancy hemangiopericytomas, which are cured by extensive local excision, and high malignancy hemangiopericytomas frequently tending to recur and form distant metastases in spite of intensive therapy. There are also borderline or intermediary types where the clinical course is extremely difficult if not impossible to predict. According to current knowledge, 
the prognostic factors include size of the primary tumor $(>5 \mathrm{~cm}=$ poorer prognosis $)$, number of mitosis ( $>4$ per 10 high power fields), high grade of cellularity, immature or pleomorphic cells, necrosis, and hemorrhage $[6,7]$. Hemangiopericytoma is generally treated by extensive tumor excision with adjuvant radiotherapy and chemotherapy, but radical surgery, if possible, is the mainstay of treatment for these neoplasms $[3,6,8-10]$. Hemangiopericytoma has some interesting clinical features. One of these is the rate of recurrence, which is as high as $52 \%$ of cases, mostly at distant sites, i.e. the lungs, liver and regional lymph nodes, necessitating long-term follow-up after surgical resection with additional treatment $[8,9]$. However, effective chemotherapy regimens and molecular targeting therapy have not been established yet. Adjuvant chemotherapy is unproven but can be considered. For patients with advanced disease, various chemotherapeutic regimens may result in meaningful responses in a minority of patients. Several groups have observed that doxorubicin, alone or in combination with other agents, can achieve response [9]. Mulamalla et al. [11] described a favorable clinical benefit with sunitinib, an oral inhibitor of vascular endothelial grow factor receptor. Although some tumor regressions have occurred in response to radiotherapy, hemangiopericytomas generally are believed to be radioresistant [9]. Another interesting features are various paraneoplastic syndromes accompanying this tumor, such es hypoglycemia $[8,12]$, neurofibromatosis or von Recklinghausen disease [13]. Several mechanisms, such as the secretion of insulin-like substances, insulin-like growth factor II by the tumor, and the hyperutilization of glucose have been proposed as possible causes of tumor-related hypoglycemia.

The development of hemangiopericytoma in the small bowel (ileum) is rare - to our knowledge, only few cases were reported in the literature until the end of 2007 [14]. However, none of the reports had patient monitoring as long as ours. In our patient, prognostic factors were borderline (size of primary tumor $>5 \mathrm{~cm}$, number of mitosis $4 / 10$ high power fields, with fields of necrosis and hemorrhages). Therefore and since the patient was expected to conceive in the near future, local tumor excision was not followed by adjuvant therapy. The patient was clinically followed up at 3-month intervals during the first year, every six months during the next two years and once a year during ten years. At 56 months postoperatively the patient was free from subjective discomfort, with normal clinical and laboratory findings, and pregnant. No paraneoplastic phenomena were noticed during monitoring. However, considering the high rate of hemangiopericytoma recurrence (Matsuda et al. [12] reported a patient with recurrences developing over a period of about ten years), long-term follow-up was required. Because of that, after the first birth, the patient was clinically followed once a year. After ten years, the patient was well, healthy and a mother of two healthy children.

Table 1. Laboratory findings

\begin{tabular}{ll}
\hline ESR & $90-145$ \\
$\mathrm{~L}$ & $15.7-17.7 \times 10^{9} / 1$ \\
& $(\mathrm{PMN} 70-83 \% ;$ band 5-2\%; ly 19-9\%) \\
$\mathrm{E}$ & $4.18-3.93 \times 10^{9} / 1$ \\
$\mathrm{Hb}$ & $88-80 \mathrm{~g} / \mathrm{l}$ \\
$\mathrm{Plt}$ & $309-456 \times 10^{9} / 1$ \\
\hline
\end{tabular}




\begin{tabular}{r|l|l|l} 
Case Reports $/ \mathrm{h}$ & $\begin{array}{l}\text { Case Rep Gastroenterol 2008;2:494-498 } \\
\text { D0I: 10.1159/000178167 }\end{array}$ & Published online: December 5, 2008 & $\begin{array}{l}\text { O 2008 S. Karger AG, Basel } \\
\text { ISSN 1662-0631 } \\
\text { www.karger.com/crg }\end{array}$ \\
\hline
\end{tabular}

Fig. 1. Abdomen and pelvis minor echotomography showing a well-demarcated tumorous formation.

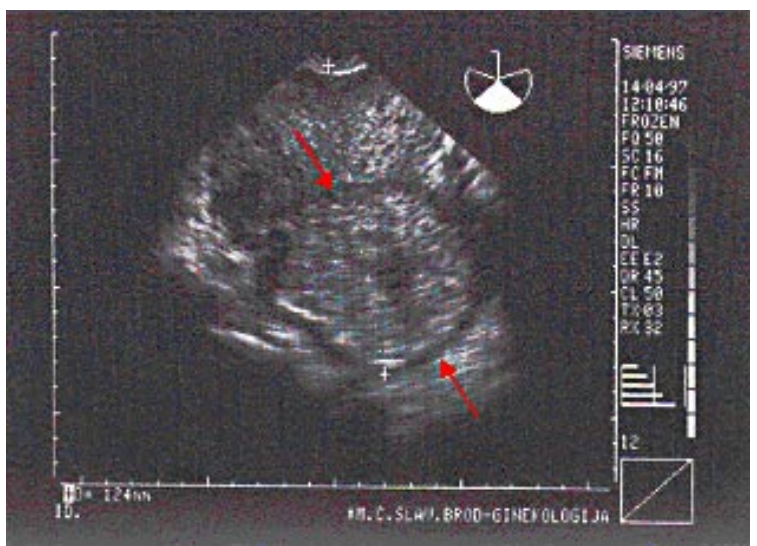

Fig. 2. Hemangiopericytoma (Gomori staining).

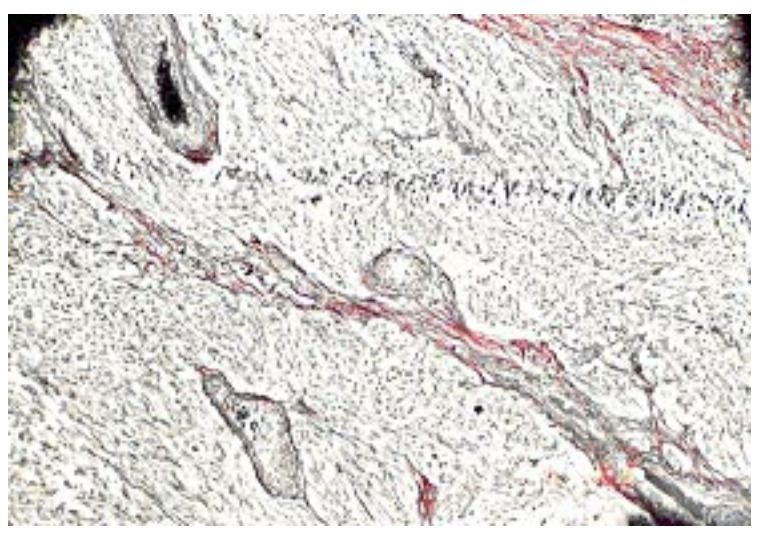




\section{References}

1 Pricolo VE, Rodil JV, Vezeridis MP: Extraorbital sebaceous carcinoma. Arch Surg 1985;120:853-855.

2 Brennan MF, Casper ES, Harrison LB: Soft tissue sacroma; in DeVita VT, Hellman S, Rosenberg SA (eds): Cancer. Principles \& Practice of Oncology, vol 2, ed 5. Philadelphia/New York, Lippincott-Raven Publishers, 1997, p 1750.

-3 Finn WG, Goolsby CL, Rao MS: DNA flow cytometric analysis of hemangiopericytoma. Am J Clin Pathol 1994;101:181-185.

-4 Cucinotta E, Gorgone S, Palmeri R, Lorenzini C, Melita G: Hemangiopericytoma: diagnostic-therapeutic considerations. Chir Ital 1995;47:50-53.

5 Fujita A, Minase T, Takabatake H, Tagaki S, Sekine K: A case of primary malignant hemangiopericytoma of the lung with marked response to combination chemotherapy with cisplatin, ifosfamide and gemcitabine. Gan To Kagaku Ryoho 2001;28:373-376.

6 Morandi U, Stefani A, De Santis M, Paci M, Lodi R: Preoperative embolization in surgical treatment of mediastinal hemangiopericytoma. Ann Thorac Surg 2000;69:937-939.

7 Vadlamani I, Ma E, Brink DS, Batanian JR: Trisomy 15 in a case of pediatric hemangiopericytoma and review of the literature. Cancer Genet Cytogenet 2002;138:116-119.

-8 Noda N, Hasegawa H, Kanai M, Shimizu Y, Yoshida H, Matsumoto T, Akita M: Recurrent hemangiopericytoma of the liver: report of a case. Surg Today 1995;25:72-75.

-9 Cajano P, Heys SD, Eremin O: Haemangiopericytoma of the greater omentum. Eur J Surg Oncol 1995;21:323-324.

10 Koch M, Nielsen GP, Yoon SS: Malignant tumors of blood vessels: angiosarcomas, hemangioendotheliomas, and hemangiopericytomas. J Surg Oncol 2008;97:321-329.

$\checkmark 11$ Mulamalla K, Truskinovsky AM, Dudek AZ: Rare case of hemangiopericytoma responds to sunitinib. Transl Res 2008;151:129-133.

12 Matsuda S, Usui M, Sakurai H, Ogura Y, Shiraishi T: Insulin-Like growth factor II-producing intra-abdominal hemangiopericytoma associated with hypoglycemia. J Gastroenetrol 2001;36:851-855.

13 Wang J, Vargas H, Gaal K, Wang X, Peng SK: Malignant hemangiopericytoma arising in neurofibromatosis: A case report with histological, immunohistochemical and ultrastructural studies. Sarcoma 1999;3:135-139.

14 Neilly PJ, Cooper GG, O'Hara MD, McGrady BJ: Ileal hemangiopericytoma and von Recklinghausen's disease. Br J Clin Pract 1992;46:212-213. 